\title{
ADULT EDUCATION FOR PEOPLE WITH EPILEPSY - MODIFICATION OF INTERNATIONAL EDUCATIONAL PROGRAM TO NATIONAL NEEDS
}

\author{
Polina Sediene \\ Lithuanian University of Health Sciences, Lithuania \\ Jolanta Pivoriene \\ Mykolas Romeris university, Lithuania
}

\begin{abstract}
The aim of the article is to discuss the process of piloting and modification of educational program for people with epilepsy, to present its implementation and countryspecific evidence-based modifications which were influenced by sociocultural situation in the country and were made based on course's participants experience. The article is grounded on the theoretical, legal documents analysis and data of participatory research with reflection of professional experience.

The changes in the program in Lithuania were caused by specific sociocultural context in the country: there was lack of specialised psychosocial services for people with epilepsy, domination of biomedical model in treatment and services, recognition of disability in relation to working capabilities, high permanent unemployment, dependency of people with epilepsy on medical staff and family, lack of reflection skills, etc. The main modifications were: prolonged duration of the training and slowing the intensity of the training what gave possibility to train reflection skills; added new topics to the Program; the Program was complimented with participatory research. Participatory research revealed that made changes during the Program's testing and modification process allowed participants to learn new skills, to tell illness narratives, to express hidden feelings, to take bigger responsibility for own illness, to formulate life goals and to plan next steps in life. The methodology of social pedagogy was used for the implementation of the Program, that it could meet the needs of the training participants and correspond to the national context.
\end{abstract}

Keywords: evidence-based modifications, MOSES - The Modular Service Package Epilepsy, people with epilepsy, social pedagogy.

\section{Introduction}

The Modular Service Package Epilepsy - MOSES is an educational program developed by professionals in the field of epilepsy to train and support people with epilepsy. Only trained and certificated professionals can implement the Program. Since the publication of MOSES in 1998 it was widely used in German speaking countries (Germany, Switzerland, and Austria) epilepsy centres and other institutions specialized on the care of people with epilepsy. The 
overwhelming majority of the participants responded highly positive and reported that co-operation between service providers and patients was strongly improved by MOSES. Seeing the Program's success and importance for target groups, there was a growing international interest in such countries as England, Denmark, Netherlands, France, and Hungary. However, to use MOSES in other countries, it was necessary to translate the program to national language and to do countryspecific modifications. Such adjustments were made in non-German speaking countries: Japan, former Czechoslovakia and Lithuania. The first MOSES educational program in Lithuania was implemented in Psychosocial Consultation for Persons with Epilepsy Centre in 2014. The first edition of the Program in Lithuania showed necessity for the modifications as the sociocultural situation in the Program origin country Germany and The Program piloting country Lithuania was different. In 2018 the Program was implemented for the group of people with epilepsy who were attending Day Occupation Group. During the Program implementation in 2018 a participatory research was done in order to find out what additional changes are needed in the Program.

The aim of the article is to discuss the process of piloting and modification of educational program MOSES, to present its implementation and countryspecific evidence-based modifications which were influenced by sociocultural situation in the country and were made based on course's participants experience. This process was based on the methodology of social pedagogy as it is understood in German social pedagogy approach. Social pedagogy in the German sociocultural context means supporting the people in different situations and various phases of life. It includes preventive, counseling, pedagogical and therapeutic activities in attempt to find the balance between the needs of the individual and society (Kolleg für Sozialpädagogik, 2021).

In two following subchapters the process of piloting and modification of the Program is described. Firstly, based on theoretical, legal documents analysis and reflection of professional experience the changes caused by different sociocultural countries: The Program origin country Germany and the Program piloting country Lithuania are discussed. Secondly, the data of participatory research is presented. The research was implemented by certificated MOSES professional who already had experience in implementing the Program, therefore, could observe the process of learning from outsider and insider positions. During ten meetings she collected stories of nine Program participants and after content data analysis summarised additional needed changes.

\section{Modifications Based on Specificity of Sociocultural Situation}

MOSES started in 1998 in Germany and spread after that in other countries. It is an educational program developed by professionals in the field of epilepsy to 
support people with epilepsy to become "experts" of their conditions through a better knowledge of diagnostic and therapeutic procedures, to understand possible psychosocial consequences of epilepsy and to cope actively with them, to live with as little epilepsy related restrictions as possible. The target groups of the program are persons with epilepsy irrespective of type and severity up from 16 years, and their partners or their relatives. Participants should be able to follow training sessions of about 90 minutes and be able to make personal notes (Baier et al., 2020).

MOSES is a modular program of education for people with epilepsy and their relatives, based on social pedagogy approach, the concept of comprehensive care, grounded on the view that the state of epilepsy consists not only of seizures, but also of the mental and social situation of human life. The content and didactics of the Program are designed to motivate people with epilepsy to participate actively in treatment and shaping their lives, to provide them with knowledge and models that enable them to act independently (Pfaefflin, Fraser, \& Thorbeche, 2001). Participants of the Program gain medical knowledge about epilepsy, understand better their disease and subjective experience of living with the illness, strengthen self-confidence and confidence in others. People communication and cooperation in a group with each other and with MOSES teachers during the training helps to get rid of tension and anxiety, to overcome the fear of stigma, to gain the freedom in making and implementing decisions that increase their personal well-being (Sedienè, 2017).

Since the initiation of MOSES in 1998 it has been widely being used in German epilepsy centres and other institutions specialized in the care of people with epilepsy. One of the first evaluation study with 242 patients from Germany, Switzerland and Austria showed that overwhelming majority of the participants responded to the Program highly positive. Data proved that co-operation between physicians and patients strongly improved by MOSES. Patients who have participated in MOSES had greater knowledge about epilepsy, had more active coping strategies in comparison to control persons without training. At the same time seizure control had improved and less side effects of medication were reported (Pfaefflin et al., 2001).

As the effectiveness of the Program was proved, it spread in other, nonGerman speaking countries. The first MOSES educational program in Lithuania was implemented in 2014 by the professional who got training in Germany. However, a huge sociocultural difference between the countries called for necessity to modify the Program.

Compared to the situation in Germany, Lithuania does not have well developed psychosocial support system for people with epilepsy. In Germany, epilepsy centers have been operating for more than 100 years, providing psychosocial services in addition to medical services, epilepsy counseling centers 
have been operating throughout Germany (Kleinwachau - Saxon Epilepsy Center Radeberg, 2021). In Lithuania, epilepsy was and still is treated exclusively by medical means and no specialized model of complex biopsychosocial care has been developed. Therefore, persons with epilepsy in Lithuania do not have the skills to seek psychosocial help, to use psychosocial and psychoeducational services. The biomedical model of health care still prevails in Lithuania, the unequal, paternalistic doctor-patient relationship remains, forming a greater dependence of people with epilepsy on doctors, family members and relatives.

In Germany, MOSES training is provided in epilepsy centers, epilepsy counseling centers and it is an integral part of epilepsy treatment therefore paid by patients (health insurance) funds. This provides an opportunity to formalize MOSES training, on the other hand, a formalized program frames the duration of training depending on payment. In Lithuania, MOSES education program is funded via projects activities therefore could be more flexible. Lithuanian participants of the training are attending Day Occupation Group for a long duration and have the opportunity to participate in the Program longer. Having such conditions, the duration of the Program has been extended from 2 intensive days as in original program to 2.5 months, having classes two days a week for 2 hours what has led to less intensity and bigger continuity.

In Germany original training is provided for people with epilepsy, often working and living independently. Meanwhile, in Lithuania, most people with epilepsy live with their parents and relatives, leading dependent life. This called for necessity to revise the Program content and to add new topics directed toward strengthening independent living competence.

Part of the people with epilepsy has a disability. The situation of the people with disabilities in Lithuania differs from the ones in Germany. In Lithuania the determination of level of disability is related with working capacity and effects the income. In Lithuania, people with epilepsy and disability are not motivated to work as their disability allowance could decrease in the case of employment. On the other hand, employers are not ready to hire people with epilepsy because they do not know specificities of the disease, they underestimate them, do not give the opportunity to work and achieve the results at work (Sediene,, Pivoriene, \& Laskeviciute, 2017). Modification of MOSES training in Lithuanian aimed to empower people with epilepsy for employment, to prepare them for an interview with potential employer and further communication in working place. Better knowing individual aspects of own illness and abilities to work, people with epilepsy can explain to employers the real personal situation and thus to increase the possibilities of the employability.

In Germany, in the case of failure to integrate people with epilepsy into the labor market, another opportunity is used - they are employed in social enterprises. German epilepsy centres have specialized kindergartens, schools, 
vocational training, and integrated workplaces where people with disabilities work together with other members of the community. Lithuanians lack such possibilities. People with epilepsy experience greater isolation and exclusion therefore, modifying MOSES program according to the Lithuanian context, it was necessary to study the availability of educational and psychosocial services for people with epilepsy, to provide them information, also to strengthen personal coping strategies by giving more space to sharing experiences, the expression of negative feelings, gradually moving from doing nothing to searching for solutions.

In Germany, regular psychosocial services, the opportunity to work and live independently allow people with epilepsy to use MOSES training more consciously and effectively, while MOSES training in Lithuania was primarily focused on understanding of own illness, reflection of life with epilepsy experience, recognition of feelings and their experiencing. Thus, it was sought to „open the space" for real changes and in addition to the standard training topics, additional topics were introduced: interpersonal relationships between group members; the relationship of the group members with the group leader; the attendance of Day center in connection with life goals, etc.

After evaluating above mentioned facts: inadequacy of psychosocial support system, the Program implementation, payment and duration possibilities, people with epilepsy dependence on others, long-term unemployment, MOSES program was strengthened with social pedagogy methodology. Six stages social pedagogy methodology defined by M. Heiner (2004) was applied during the Program implementation and it also was a core of participatory research. First, the questionnaire was used to collect data about the participants: illness duration, type and frequency of epileptic seizures, living conditions, treatment circumstances, and so on. In another stage collected data was validated during interviews what allowed to obtain the subjective experiences of the training participants and to give meaning to these experiences. The third stage of the training was for revealing the successes and failures of the treatment and the ways how family members involved in the treatment. After re-summarizing and assessing all gathered information, in the fourth stage of the training pedagogical activities and interventions, including art therapy methods, were applied. In the fifth phase of the training program, people with epilepsy get better understanding of the situation of their lives with epilepsy. In the final stage it was discussed and documented what was effective in the training, and participants formulated their future goals. 


\section{Modifications Based on Participatory Research Data}

Aiming to adjust the Program to national needs the participatory research was implemented in 2018. It was done by certificated MOSES professional who provided the training and at the same time participated in people with epilepsy story telling. Data of ten meetings with the participation of nine people was analysed using qualitative content data analysis method which revealed these categories: involvement in the Program by agreement on learning objectives and common rules; continuous analysis of the effects of epilepsy on the personality as a way to reflect on personal experiences. The will to participate and continentality were ensured during the research.

Involvement in the Program by agreement on learning objectives and common rules. At the beginning of MOSES training, one meeting was planned to discuss learning objectives and common group rules. Such in-depth discussion is not foreseen in the original German program.

During the discussion participants showed high involvement in the process:

"I would like to meet a person who knows how to live with epilepsy, that the illness does not affect him, that he cannot do anything, that he cannot work" (A).

The data shows that there is a need to share experience, to talk about the illness and life with it, to learn living valuable life, regardless the consequences of illness.

MOSES teacher asked the participants to review the positive aspects of the illness and they told:

"I consider it as an advantage as 24 hours a day I can be with my child, there would not be such opportunities if I wouldn't be ill" (V). "At the beginning I was asking myself - why did I get that disease - but then I thought, what can I do, I have to live with that. What it would change, if I will be sitting and waiting for a seizure, my whole life will pass by" (A).

One of the most important rules which is discussed during the meeting is confidentiality. It could be understood in various ways, it depends on environment in which with whom information is shared and reflected.

" $<\ldots$... it is important to talk about seizures, good that there is training to share that with others. Anyone can talk everything about me. When it was a seizure in the group, I haven't told about that when I went home. For me, it doesn't matter, if you will take information about me and use it somewhere" (V).

This excerpt from the interview shows that it is safer to talk about illnessrelated experiences in Day Occupation Group than at home.

People with epilepsy prefer "partial confidentiality":

"When I returned from a group home after someone's seizure in the group, emotions arise, so it is possible to share with friends or parents, but it is not necessary to name the person" (A).

Disclosure of teaching content to close people is considered a natural thing:

"I only talk to my mother. What tasks do we do, our talks" (L). 
The topic of confidentiality also includes the rules that define the relationship between the members of a group:

"Everyone can say what he wants to say, respecting the other when it comes to illness; how we should be together, how we want to be together" (V).

Discussion of the general rules in the group allowed to analyze various attitudes and experiences related to whom and how to tell about the illness, also the importance of personal responsibility, a feeling of personal boundaries. It also revealed the phenomenon of hiding the illness, when a family resist to talk to others that a daughter or son has epilepsy:

"Mom always told me why do you talk, keep quiet, don't tell anyone. $<\ldots>$ My mother is a beautiful, kind woman, but she has fears, she is afraid that her value will decline, that she will be no longer the same in others' eyes, if they found out that her daughter is disabled, that she lives with her for 34 years" (V).

A detailed discussion of the confidentiality revealed the experiences of participants in the group and in the families. There are social environments in which people thoughts are perceived as meaningless and incorrect (Laing, 2002). In such environments, people avoid talking about illness or epileptic seizures, and such an unfavorable environment sometimes become families. The Day Occupation Group becomes only safe environment to reflect personal experience.

Made modifications allowed sufficient time to discuss common training rules and objectives. The importance of confidentiality for involvement in training and research was emphasized. It was explained how confidentiality is understood by the training participants, what forms of confidentiality are acceptable in which situations. It was decided that the form of confidentiality could be defined differently depending on where, in what environment and with which people the experience is shared and reflected. Sensitive issues related to confidentiality have been identified. It turned out that in Psychosocial Consultation for Persons with Epilepsy Centre it is safer to talk about experiences related to the illness than at home. A detailed discussion of the general rules of the group allowed to analyze various attitudes and experiences related to whom and how to tell about the disease, the importance of personal responsibility, a sense of personal boundaries.

Continuous analysis of the effects of epilepsy on the personality as a way to reflect on personal experiences. Personal identity is formed through social relationships. Other people reactions to the limitations and possibilities of ill person life, society's attitudes towards certain situations in a person's life, such as illness or disability, are important for the formation of identity. But no less important is self-knowledge, creating and re-creating narratives of one's life, making personal choices in shaping self-identity. Identity is formed during the whole person's life. This process can be called a journey into self-acceptance, which is only possible through a relationship with others. Self-acceptance allows to integrate all aspects of one's personality, strengthens conscious participation in public life, increases confidence. When it comes to epilepsy, which is stigmatized, 
it should be emphasized that the integration of the illness into identity is highly dependent on the development of professional relationships between people with epilepsy and services providers, development of services which supports the human dignity services in society (Sedienè, 2020). Therefore, modifying MOSES educational program according to local/national needs involves long-term processes: building the relationship between the teacher and the participants, the opening of the space for narrative without time pressure and not limiting the topics included in original Program. One of such topics become reflection on outset of the illness. The answers differed for those participants who got epilepsy in early childhood and those who became ill in late adolescence:

"Well, I was healthy for 1-1.5 years, and then I have to learn everything again, to sit, to walk. It is very difficult for me to compare, because I don't remember myself healthy" (A).

"I felt like a bag of potatoes fall on me .... I have been taking medicine since the age of 14, the illness has changed me for the worse, but also for the better, it gave me strength, I am fighting. I don't know if I would have discovered my strength if I had been healthy all my life" (V).

"I needed time, I studied at vocational school, I was not allowed to choose a profession I wanted, I can't go to the pool..." (L).

"I lived with problems, I was used to them, but when I had epilepsy, I had to learn everything again. I had epilepsy when I was 20 years old. I was locked up at home for seven years" $(R)$.

Epilepsy, which starts in adulthood, can destroy a person's sense of self and confidence in one's body, what calls for the adoption of various strategies to manage the threat to the identity (Kılınç, Campbell, Guy, \& Wersch, 2018). Research data revealed that MOSES teachers need to pay attention to the impact that epilepsy can have on an adult person's identity and confidence in the body.

People with epilepsy, like others, want to be seen as individuals, not just as ill persons. This is evident in analyzing the challenges children face when they reveal their illness to others as Benson et al. (2015) wrote "I don't want them to look at me and think about my illness, I just want them to look at me and see me". Research participants say:

"I was told - you are not going to school, the teacher will come to you, I can say that I spent 4 years alone at home" (A). "I was locked up, they were saying me - you can't do this, you can't do that" (L). "They chose for me a vocational school, they said that the environmnt will be good, but it was terrible" (La).

Like their peers, people with epilepsy dream of jobs that match their talents and hobbies. However, the research revealed that people with epilepsy face limitations. Their parents, teachers, employers do not go deep into the specifics of seizures, do not listen to person's wishes, do not assess abilities, but decide solely on the diagnosis of epilepsy and therefore people with epilepsy cannot realize professional dreams:

"You can't work in the profession you dream of" (R). 
With epilepsy, it becomes unsafe to live because people cannot rely on their social competencies:

"I became a baby in the family, I can't do anything, it stops me in my profession, I was locked up at home for my leisure time. What I've learned for so many years doesn't go out to do. Suddenly you find out that you have epilepsy, I lost documents on how to shop, pay taxes" $(R)$. "Losing, in fact, if losing a child, people take a girl, even though she knows that I have seizure, she knows that it is impossible to talk to her mother, but others accuse me saying that I am alcoholic, drug addict" (V).

People with epilepsy experience disempowerment, not listening to their opinion. Sometimes it leads to resistance:

"Parents, guardians are responsible, but I want to be responsible for my life. I talk, consult with my child, I will never treat her the way I was treated" (V). "I'm told to do that, do that, and I'm used to give a report in every step, I'm writing a message in a while as a report, it is already in my blood" (L). "It doesn't matter that I'm ill, but I can live. I was 16-18 years old, treated like a toy which needs the help, parents themselves enforces that feeling, and after that get angry that as an adult I am dependent. They taught me that I can't do anything, I can't teach anything" $(V)$.

Hypercare raises variety of fears. People with epilepsy are not satisfied with their level independence and relations (Geerlings, Gottmer-Welschen, Machielse, Louw, \& Aldenkamp, 2019). The stories of the research participants show that they have changed not only because of illness itself, but also because of the behavior of family members. A failed transition to independence causes loneliness and effects identity. The development of the identity of a person with a chronic illness relates with a physical condition, impaired bodily functions, loss of social positions, inability to perform certain role in society, threats to material well-being and mental health, and threats to self, one's environment and one's life (Beland, 1985).

Majority of people with epilepsy said that it has changed them - they needed to take medication, they have challenges in education, they needed to follow a strict regime. Everyone in the group had different experiences, therefore it was important to hear everyone, to try to understand, to find explanations and to help reflecting the experience in writing and orally. Continuous, repeated analysis of the effects of epilepsy on the personality helped the participants to express their negative feelings that arose due to their own helplessness in epilepsy, overestimated control of close people, and difficulty in learning to live a new life with the illness. Active listening, giving enough time to narratives, slow tempo, safe environment provided for participants a space for the development of reflection skills.

\section{Conclusions}

MOSES aims to highlight opportunities, it encourages to become an ambassador of own illness. This requires the development of knowledge, skills 
and personal qualities. At the same time, it is important to understand the limitations and accept reality as it is.

The necessary changes in the program in Lithuania were caused by specific sociocultural context in the country: there was lack of specialised psychosocial services for people with epilepsy, domination of biomedical model in treatment and services, recognition of disability in relation to working capabilities, high permanent unemployment, dependency of people with epilepsy on medical staff and family, lack of reflection skills, etc. The main modifications were: prolonged duration of the training and slowing the intensity of the training what gave possibility to train reflection skills; integration of various art therapy sessions what facilitated learning and acquiring needed competences. Participatory research revealed that made changes during training program's testing and modification process allowed participants to learn new skills, to tell illness narratives, to express hidden feelings, to take bigger responsibility for own illness, to formulate life goals and to plan next steps.

The methodology of social pedagogy chosen for the implementation of the Program in Lithuania allowed to look deeper into the subjective experiences of the training participants and to modify the Program using social pedagogical methods and interventions.

\section{References}

Baier, H., Coban, I., Dennig, D., Geiger-Riess, M., Haferkamp, G., Kerling, F., Lippold, M., Scheid, B., Specht, U. (2020). MOSES Er-Arbeitungsbuch. Modulares Schulungsprogramm Epilepsie. 4 Auflage. Bielefeld: Bethel.

Beland, H. (1985). Zur Bedeutung chronischer Krankheit für die Identität der Betroffenen. Soziale Welt 36., H. 3, 349-365. Retrieved from https://www.jstor.org/stable/408774446

Benson, A. Toole, S.O., Lambert, V., Gallagher, P., Shahwan, A., \& Austin, J.K. (2015). Tell or not to tell: A systematic review of the disclosure practices of children living with epilepsy and their parents. Epilepsy \& Behavior 51, 73-95. DOI: http://dx.doi.org/ 10.1016/j.yebeh.2015.07.013

Geerlings, R.P.J., Gottmer-Welschen, L.M.C., Machielse, J.E.C, Louw, A.J.A., Aldenkamp, A.P. (2019). Failed transition to independence in young adults with epilepsy: The role of loneliness. Seizure: European Journal of Epilepsy, 69, 207-212.

Heiner, M. (2004). Diagnosen - das ungeliebte Handwerk. In Diagnostik und Diagnosen in der sozialen Arbeit. Ein Handbuch. Berlin, Eigenverlag des Deutschen Vereins für äffentliche und private Fürsorge.

K1lınç, S., Campbell, C., Guy, A., Wersch, A. (2018). Epilepsy, identity, and the experience of the body. Epilepsy Behavior, 89, 42-47. DOI: https://doi.org/10.1016/j.yebeh. 2018.10.003

Kleinwachau - Saxon Epilepsy Center Radeberg. (2021). Retrieved from https://www.kleinwachau.de/suche?tx_kesearch_pi1\%5Bsword\%5D=Geschichte

Kolleg für Sozialpädagogik. (2021). Was ist Sozialpädagogik? Retrieved from https://www.sozialpaedagogik.at/sozialpaedagogik/was-ist-sozialpaedagogik.html 
SOCIETY. INTEGRATION. EDUCATION

Proceedings of the International Scientific Conference. Volume III, May $28^{\text {th }}-29^{\text {th }}$, 2021. 414-424

Laing, R. (2002). Ja i drugie. Moskva: JEKSMO-Press.

Pfaefflin, M.T., Fraser, R.T., Thorbeche, R. (2001). Comprehensive Care for People with Epilepsy. London: John Libbez\&Company.

Sedienè, P. (2017). Pratarmè. In Moses (eds.), Moduline epilepsijos mokymo programa. Darbo knyga, (5 - 6). Kaunas: Caritas.

Sedienė, P., Pivorienè, J., Laskevičiūtè, E. (2017). Epilepsija sergančių asmenų patirtys darbo rinkoje ir socialinès pagalbos galimybès. Socialinis darbas: patirtis ir metodai, Nr. 20 (2), 99-115. DOI: https://dx.doi.org/10.7220/2029-5820.20.2.5

Sedienè, P. (2020). Epilepsija sergančiu asmenu psichosocialiné situacija. Tarpdalykinès komunikacijos ir kūrybiško bendradarbiavimo prielaidos. Kaunas: LSMU leidybos namai. 